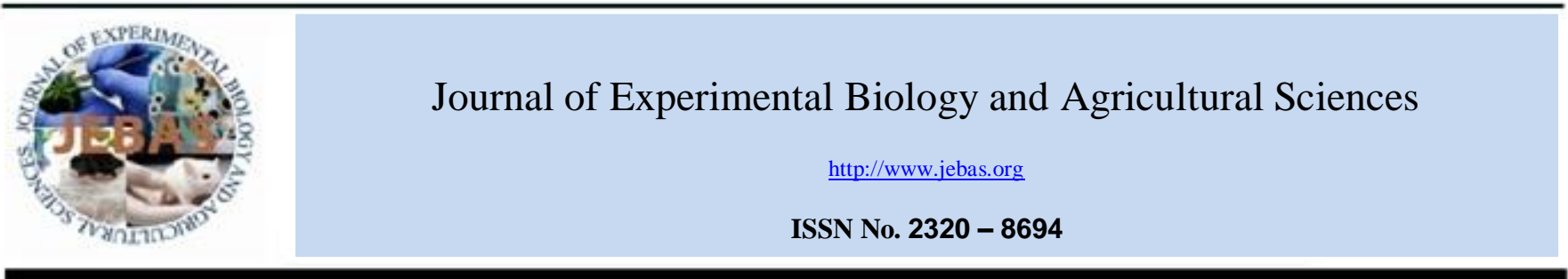

\title{
EFFECT OF DELETION MUTATION IN THE DIHYDROFLAVONOL 4-REDUCTASE (DFR) ON ANTHOCYANIN PRODUCTION IN GREEN COLOR MANGO VARIETY (Mangifera indica var Guiqi)
}

\section{Zhao zhichang $^{1,2^{*}}$, Gao aiping ${ }^{1,2}$, Huang jianfeng ${ }^{1,2}$, Luo ruixiong ${ }^{1,2}$, Liu kuanliang ${ }^{1,3}$}

\footnotetext{
${ }^{1}$ Tropical crops genetic resources institute Chinese academy of tropical agricultural sciences/key laboratory of crop gene reso urces and germplasm enhancement in southern China, Hainan Haikou ,571101.

${ }^{2}$ National Cultivar Improvement Center of Tropical Fruit Tree, Hainan Haikou 571101.

${ }^{3}$ College of agriculture Hainan University, Haikou, 570228.
}

Received - January 24, 2019; Revision - March 19, 2019; Accepted - April 04, 2019

Available Online - April 10, 2019

DOI: http://dx.doi.org/10.18006/2019.7(2).204.210

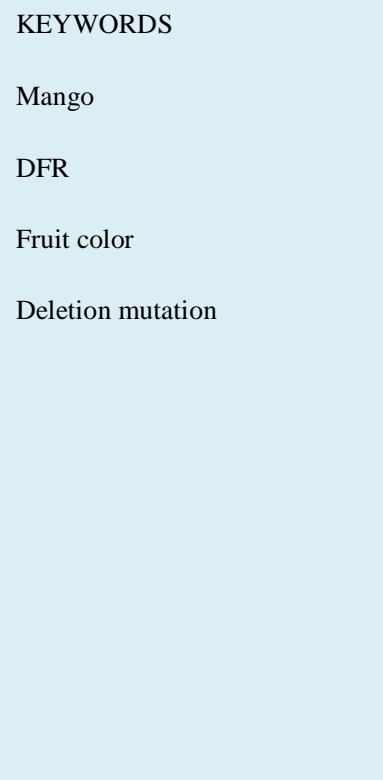

\author{
ABSTRACT

\section{Abbreviations} \\ DFR - Dihydroflavonol 4-reductase; \\ NADPH - Nicotinamide adenine dinucleotide phosphate; \\ DNA - Deoxyribonuleic acid; \\ $C T A B$ - Hexadecyl trimethyl ammonium bromide; \\ RACE - Rapid amplification of cDNA ends; \\ $O R F$ - Open reading frame; \\ ANS - Anthocyanidin synthase
}

Fruit color in mango (Mangifera indica) is an important trait, but the mechanism of green color inheritance is poorly understood at the molecular level. The present study revealed that in contrast with red mango fruits ( $M$. indica var. Guifei), less anthocyanin production was reported in green mango fruits ( $M$. indica var. Guiqi) during ripening, which was a result of reduced activity of the dihydroflavonol 4-reductase (DFR) enzyme at the translational level. The sequences of the DFR gene in these two varieties are partially similar, except for a single base-pair change at the $116^{\text {th }}$ base position and an approximately 74-bp deletion within the middle portion of the green color DFR gene. The sequence of the DFR protein showed different lengths, consisting of 194 and 328 amino acids in 'Guiqi', and 'Guifei'. The deletion mutation in the green color DFR gene greatly reduced anthocyanin contents in green, 'Guiqi' mango fruits.

* Corresponding author

E-mail: zhaozhichang2001@163.com (Zhao zhichang)

Peer review under responsibility of Journal of Experimental Biology and Agricultural Sciences.

Production and Hosting by Horizon Publisher India [HPI] (http://www.horizonpublisherindia.in/).

All rights reserved.
All the article published by Journal of Experimental Biology and Agricultural Sciences is licensed under a Creative Commons Attribution-NonCommercial 4.0 International License Based on a work at www.jebas.org.

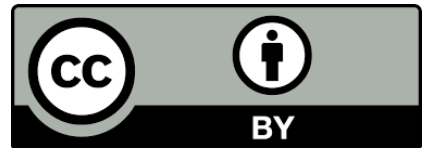




\section{Introduction}

Anthocyanin biosynthesis and metabolism produces a great number and variety of compounds (Winkel-Shirley, 2001; Park et al., 2004). These molecules play important roles in many fundamental processes of plants, such as the pigmentation of flowers and fruits, signaling, heat exchange, UV resistance, pollen fertility, defense to wounding and fungal attacks and environmental stress responses (Shirley et al., 1995; Dixon \& Piava, 1995; Moyano et al., 1996; Weisshaar \& Jenkins, 1998; Harborne \& Williams, 2000; Cominelli et al., 2005; Miller et al., 2011)). The regulation of the anthocyanin pigments in plants are particularly important in metabolic engineering applications because these compounds act as visual signals that attract the insects and animals for pollination of flower, seed production and dispersal (Holton \& Cornish, 1995). Anthocyanin biosynthesis pathway is well established, and the central pathways in this process are highly conserved in plants, such as Arabidopsis, maize and flower plants, had facilitated a sound understanding of the structural genes and transcription factors (structural genes that encode the enzymes that directly participate in the anthocyanin biosynthetic reactions, and transcription factors that regulate the expression of these structural genes and the accumulation of anthocyanin metabolites) involved and the assembly of the relevant enzyme complexes such as PAL, CHS, F3H, DFR, UFGT, MYB, WD40, b HLH etc (Winkel-Shirley, 2001; Shih et al., 2006; Sui et al., 2011; Sun et al., 2015 ; Sun et al., 2016; Li et al., 2016). The enzyme dihydroflavonol 4-reductase (DFR) catalyzes the stereospecific reduction of dihydroflavonols to leucoanthocyanidins (flavan-3,4-diol) using NADPH as a cofactor (Heller et al., 1985; Kristiansen \& Rohde, 1991; Rosati et al., 1987; Martens et al., 2002). Depending upon the plant system, leucoanthocyanidins could be utilized for the synthesis of compounds such as flavan-3-ol [(+)-catechin] as the likely start unit to oligomeric proanthocyanidins which were involved in plant resistance to heat, light, pests and diseases, and regarded as potential health-protecting food and feed (Harborne \& Williams, 2000). DFR genes had been isolated from some higher plants such as Malus domestica (Fischer et al., 2003), Pyrus communis (Fischer et al., 2003), Medicago truncatula (Xie et al., 2004), Lotus japonicus (Shimada et al., 2005), Citrus sinensis (Piero et al., 2006), Camellia sinensis (Singh et al., 2009), Populus trichocarpa (Huang et al., 2012), Ipomoea batatas Lam (Wang et al., 2013) and Ginkgo biloba (Cheng et al., 2013); recombinant proteins produced from these plants had been well characterized. Knowledge of DFR was important to understand various aspects of flavonoid biosynthesis, especially how plants regulate condensed tannins \& composition and different stereochemical features of flavan-3,4-diols and related compounds. DFR regarded as central enzyme of the flavonoid pathway and opens possibilities for metabolic engineering of the pathway (Forkmann
\& Martens, 2001). In order to study the difference color in different mango fruits, especially whether the differences in structural genes or whether theses the differences will affect the formation of anthocyanins. In the present paper, we report on the isolation of a DFR cDNA clone from different color mango peels. The identity of the clones was different by comparison of the nucleotide sequence and amino acids sequence.

\section{Materials and Methods}

\subsection{Plant materials}

Present study was conducted on 8 years old mango trees ( $M$. indica) cultivars 'Guiqi' and 'Guifei' from a commercial orchard in the harvest season of 2010 year, in Hainan Island, China. All of the experimental trees received similar cultural treatment regarding fertilization, irrigation, and plant protection. Mature green color (Guiqi) and red color (Guifei) mango fruit were collected and immediately transported to the laboratory. The fruit was sliced and frozen in liquid nitrogen.

\subsection{Detection of total anthocyanins and total carotenoids in different color mango peels}

Ground peel of mango was mixed with acid-ethanol $(0.1 \% \mathrm{HCl}$, $\mathrm{v} / \mathrm{v})$ in $15-\mathrm{ml}$ conical tubes, incubated in the dark for $10 \mathrm{hrs}$, at $4{ }^{\circ} \mathrm{C}$. The mixture was centrifuged for $15 \mathrm{~min}$ at $4000 \mathrm{rpm}$. The supernatant was collected and transferred into $15 \mathrm{ml}$ volumetric flasks for measurement of anthocyanins yield. About $0.5 \mathrm{~g}$ of the peel sample was used for each treatment. The total anthocyanin content was determined according to the $\mathrm{pH}$-differential methods (Lee et al., 2005; Yang \& Zhai, 2010). Extraction of total carotenoids from mango peel was conducted using a solvent extraction system and ultrasonication was run at room temperature. Briefly, triplicate samples of $1 \mathrm{~g}$ mango peels were ground with $20 \mathrm{~mL}$ of cold acetone $\left(4^{\circ} \mathrm{C}\right)$ in a mortar, this mixture vacuum filtered through a funnel using no. 4 filter paper that was $10 \mathrm{~cm}$ in diameter (Whatman International Ltd). The filtrate was transferred to a separation funnel together with petroleum ether and water. The two layers were allowed to separate without stirring and the lower layer was discarded. The upper ether layer washed several times with water to eliminate residual acetone. After the water was removed using anhydrous sodium sulfate, the ether phase was transferred to a suitable flask and its volume was adjusted to $10 \mathrm{~mL}$ with petroleum ether. The entire procedure was executed under low light conditions in order to prevent carotenoid degradation. Total carotenoid content of mango peels was measured spectrophotometrically using a method described previously by Davies (Davies, 1976). $2 \mathrm{~mL}$ mixture was placed in a $3 \mathrm{~cm}$ cuvette to measure the absorbance using a UV-Vis spectrophotometer (Thermo Scientific, USA) at $472 \mathrm{~nm}$ and 
$508 \mathrm{~nm}$. Absorbencies were recorded to obtain both isochromic carotenoid fractions and total carotenoid.

\section{3 cDNA and DNA of $D F R$ cloning}

DNA was isolated from fresh mango leaves samples by CTAB method (Stewart \& Via, 1993), while the total RNA was isolated from mango peel samples according to the method of Wan \& Wilkins (1994). Reverse transcription was achieved with oligo-d (T) $)_{18}$ primers by using 5 ug of total RNA isolated from mango peel and the prime Script II 1st strand cDNA synthesis kit (TaKaRa). To isolate partial cDNA clone, two oligonucleotides were designed on the basis of conserved amino acid sequences of several available DFRs: forward primer (5'GAATCCAAGGATCCYGAGAAYGA'3); reverse primer (5'AAGTACATCCATCCAGTCATYTT3'). The PCR reaction was carried out using the following conditions: $94^{\circ} \mathrm{C} 3 \mathrm{~min}(1$ cycle); $94^{\circ} \mathrm{C} 30 \mathrm{~s}, 55^{\circ} \mathrm{C} 30 \mathrm{~s}, 72^{\circ} \mathrm{C} 1 \mathrm{~min}(30$ cycles $) ; 72^{\circ} \mathrm{C} 5 \mathrm{~min}(1$ cycle). An amplification product of $260 \mathrm{bp}$ and its identity was confirmed by sequencing. The 3' RACE and 5' RACE of DFR gene was used for the rapid amplification of cDNA ends (RACE) reactions, according to 3'-Full RACE Core Set ver.2.0 and 5'-Full RACE Kit (TaKaRa in Dalian, China). A genomic DNA sequence was obtained using PCR-based methods. The reaction mixture (20ul) contained 10ng DNA, $100 \mathrm{mM}$ dNTPs, $0.5 \mathrm{mM}$ of each primer, 0.5U ExTaq ${ }^{\mathrm{TM}}$ DNA polymerase (TaKaRa), and $2 \mathrm{ul}$ $10 \times E_{\text {Taq }}{ }^{\mathrm{TM}}$ PCR buffer. The PCR parameters were one cycle of the following step program: $95^{\circ} \mathrm{C}$ for $3 \mathrm{~min}, 56^{\circ} \mathrm{C}$ for $10 \mathrm{~s}, 72^{\circ} \mathrm{C}$ for $2 \mathrm{~min}$, then 35 cycles of the following program step: $95^{\circ} \mathrm{C}$ for $30 \mathrm{~s}, 56^{\circ} \mathrm{C}$ for $10 \mathrm{~s}, 72^{\circ} \mathrm{C}$ for $2 \mathrm{~min}$, and a final extension step of $72^{\circ} \mathrm{C}$ for $10 \mathrm{~min}$. All PCR products were cloned into pMD-19T (TaKaRa in Dalian, China), using the TOPO TA cloning method.

DNA sequence compilation, nucleotide and amino acid sequence comparisons were performed using the LASERGENE DNA software package (DNAstar, Madison, WI). Sequence similarity searching was performed using the BLASTN and BLASTX, nucleic and protein databases at NCBI (http://www.ncbi.nlm.nih.gov). The phylogenetic analysis of DFRs from mango and other species was carried out by alignment with the bioEdit software (http://www.mbio.ncsu.edu/BioEdit/bioedit.html).

\subsection{Extraction and assay of enzyme activity of DFR from mango peels}

1g mango peels were ground to a fine powder with a mortar and pestle using liquid $\mathrm{N}_{2}$. The powder was then extracted with $5 \mathrm{ml}$ cold acetone then centrifuged at $12000 \mathrm{~g}$ for $10 \mathrm{~min}$, supernatant was discarded. The sediment was added $4 \mathrm{ml} 100 \mathrm{mM}$ $\mathrm{Na}_{2} \mathrm{HPO}_{4} / \mathrm{NaH}_{2} \mathrm{PO}_{4}$ extraction buffer $(\mathrm{pH} \quad 8.8), \quad 18 \quad \mathrm{mM}$ mercaptoethanol. This was then dialysed overnight against the same buffer to give a partially purified extract that was used for all enzyme assays. This fraction was centrifuged at $12000 \mathrm{x} \mathrm{g}$ for
$20 \mathrm{~min}$. All these procedures were carried out at $4^{\circ} \mathrm{C}$. The crude soluble protein extraction was test according Stafford (Stafford et al., 1982; Stafford et al., 1984).

\subsection{Prokaryotic expression and enzyme activity determination} of the dihydroflavonol 4-reductase

In order to produce fragment for in vitro expression reactions, the cDNA fragment of DFRs gene were amplified with common primer, and inserted into the vector pET32a (Novagen). The expression vector of pET32a::DFR(Guifei) and pET32a::DFR(Guiqi) were obtained. The proteins were synthesized according to the manufacture's instructions. Proteins were analyzed by sodium dodesyl sulfate (SDS) polyacrylamide gel electrophoresis on $12 \%$ gel. The cell of prokaryotic expression were collected by centrifugation, with PBS suspension washing, after centrifugation, resuspended in PBS solution $(100 \mathrm{ug} / \mathrm{ml} 0.1 \%$ TritonX-100 with lysozyme, 30min, digestion at room temperature), to break the cell in power under the condition of $200 \mathrm{~W}$, work 5S, stop 5S, 20 cycles, and repeated 3 times, the liquid is full of enzyme solution. After centrifugation, the enzyme solution was included broth supernatant enzyme solution, and the precipitation enzyme solution. Polypeptide was purified by BPERTM 6×His Fusion Protein Column Purification Kit (Pierece). The activity of the dihpdroflavonol 4-reductase (DFR) enzyme was detected.

\section{Results}

\subsection{Measurement of anthocyanins and carotenoids in two} different color mango peels

Anthocyanins and carotenoids were measured in two mango phenotypes of peels (Guiqi, and Guifei). Peel obtained from both mango phenotypes were examined for the presence of detectable amounts of anthocyanin. Result of study suggested the accumulation of $0.321 \mathrm{mg} / \mathrm{g}$ FW anthocyanins in green mango peel while this was reported $0.982 \mathrm{mg} / \mathrm{g} \mathrm{FW}$ in red mango peel (Figure 1). Simultaneously carotenoid accumulation in plant tissues was also

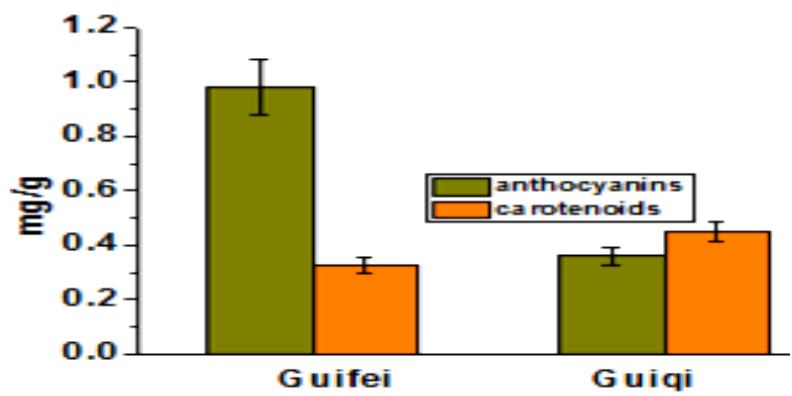

Figure 1 Total anthocyanins and carotenoids concentration in the two different colors of mango peels 


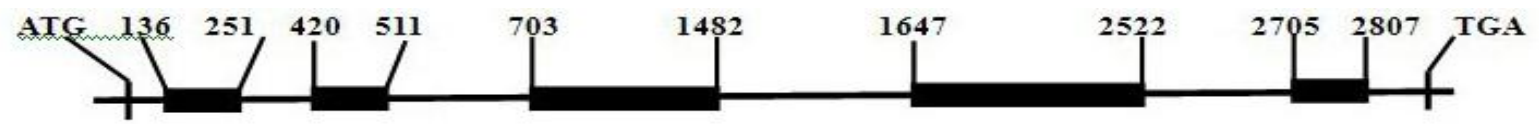

Figure 2 Characterization of DFR genomic copy (Numbers refer to position relative to the first nucleotide of the start codon. Intron was indicated by boxes, and exon was indicated by lines)

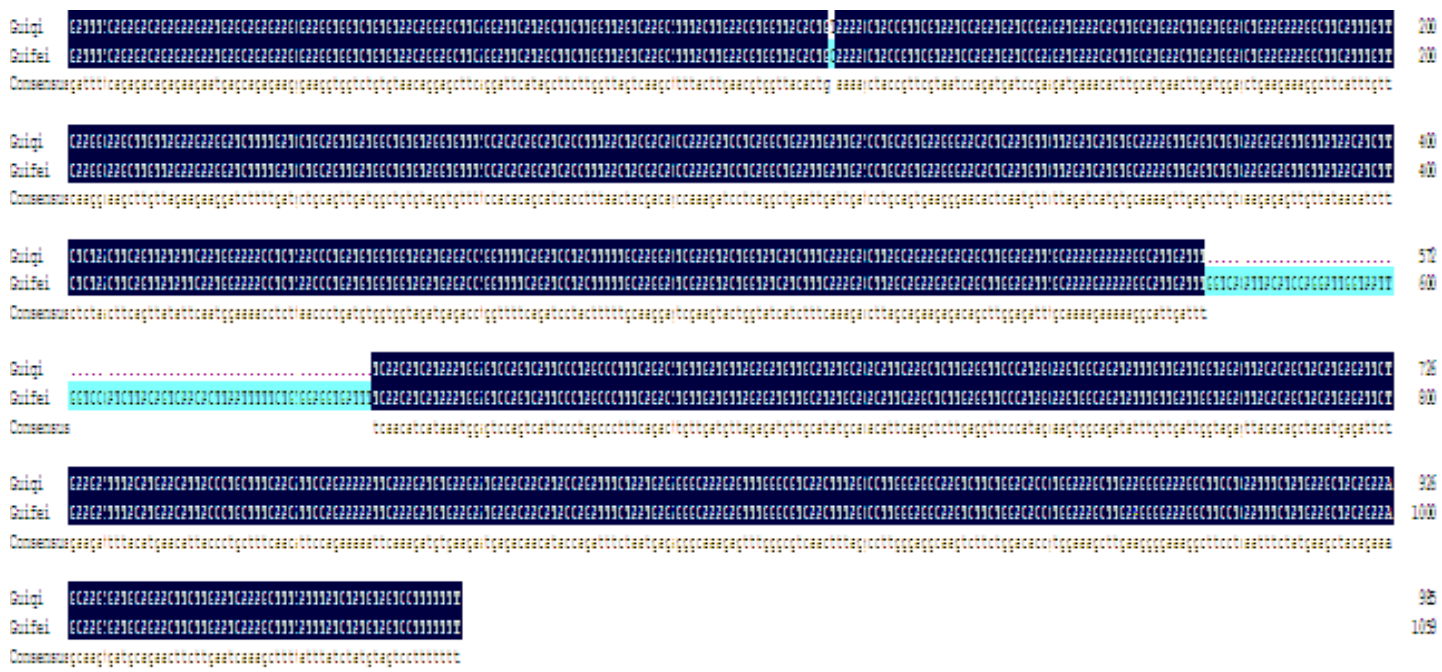

Figure 3 The cDNA structures of mango DFR gene in Guiqi and Guifei (Blue color line showed deleted region and mutation site, deep blue color line indicates the nucleotide sequence identity of homologous regions in Guiqi and Guifei mango)

measured. The presence of carotenoids contents in the green peels (Guifei) was reported higher than the red mango peels (Figure 1). Thus, red-color mango contains higher concentrations of anthocyanins than green-color mango. The red color of mango was mainly because of higher anthocyanin content and involvement of carotenoid content was not reported in red color.

\subsection{Isolation of the DFR gene from mango peels}

To obtain DFR from Guifei mango, the 260bp cDNA DFR fragments was isolated with two oligonucleotides primers by RTPCR. The entire length of the DFR cDNA was obtained by the rapid amplification of cDNA ends (RACE) reactions. The fulllength $D F R$ cDNA of Guifei mango was $1,260 \mathrm{bp}$, and the open reading frame was $987 \mathrm{bp}$, encoding 328 amino acids. The length of DFR DNA was $3,022 \mathrm{bp}$. Both sequences were observed in cDNA and DNA from mango peel, and positions 136-251bp, 420511bp, 703-1482bp, 1647-2522bp, 2705-2807bp (from the translational start site) of the genomic clones were determined to be five introns (Figure 2).The cDNA and DNA were obtained

from $30 \mathrm{ng}$ of total RNA and genomic DNA by using specific primers amplification from mango peels (Guifei, and Guiqi). Sequence analysis of DFR from different color mango peels, it was reported that isolation of a DFR gene from green mango var. 'Guiqi', shared more than $92 \%$ nucleotide sequence identity with the red mango var. 'Guifei'. The sequences of DFR in green and red mangos were partially the same, except for a single base-pair change at the 116th base position ( $\mathrm{C}$ in var. 'Guifei', $\mathrm{T}$ in var. 'Guiqi') and an approximately 74-bp deletion within the middle portion of the green color DFR gene (Figure 3 ). The sequence of the DFR protein showed different lengths, consisting of 194 and 328 amino acids in the green and the red mango variety afore cited, respectively; there was also one amino acid change at the $32^{\text {nd }}$ base position ( $\mathrm{A}$ in var. 'Guifei', $\mathrm{V}$ in var. 'Guiqi') and a difference in amino acid sequence from positions 184 to 194 (FQHHKWSPVIP in var. 'Guiqi', LVTLHPGLVIG in var. 'Guifei') (Figure 4). Genomic DNA of DFRs in different color mango did not show more difference in nucleotide sequence (data not shown).

\subsection{Enzyme activity of $D F R$ in different color mango peels}

In this study, DFR activity was detected in different color mango peel. Result of present study revealed the presence of higher DFR enzyme concentration in the red color mango (Guifei), and this enzyme concentration was followed by the green color mango (Guiqi) (Figure 5). In vitro activity assays of heterologously 

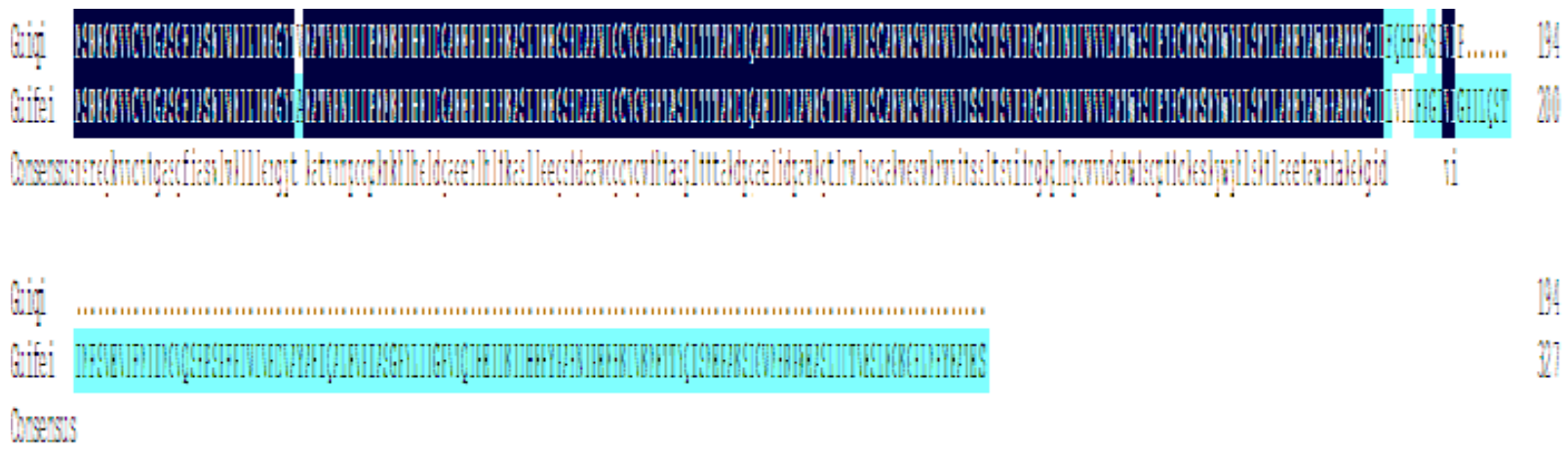

Figure 4 The amino acids structures of mango DFR protein in Guiqi and Guifei (Blue color line showed different amino acids sequence and mutation site, deep blue color line indicates the acids sequence identity of homologous regions in Guiqi and Guifei mango)

expressed proteins were performed to investigate the biochemical activity for DFR. The chimeric DFR proteins were purified using affinity chromatography, and as a control the empty vector protein extract was processed in the same manner. The observed activities are consistent with the phenotypes of peels, was higher from the red color mango and lower from the green color mango peel (Figure 6).

\section{Discussion}

Dihydroflavonol 4-redudase (DFR) played a crucial role in producing common and condensed anthocyanins, with a pivotal enzyme in the flavonoid synthetic pathway (Holton \& Cornish, 1995). Single or multiple genes encoding DFR protein(s) from plants had been reported for a few genomes (Tanaka et al., 1995; Inagaki et al., 1999; Himi \& Noda, 2004). An N-terminal NADPbinding domain that contains a highly conserved region is also present in the DFR amino acid sequence. NAD as a cofactor was from 8 to 251 amino acid sequence, dependent epimerase/dehydratase family which used nucleotide sugar substrates for a variety of chemical. 3beta-hydroxysteroid dehydrogenase (3b-HSD) like, subgroup1, extended (e) SDRs (an uncharacterized subgroup of the 3b-HSD like extended SDR family. Proteins in this subgroup have the characteristic active site tetrad and NAD (P)-binding motif of extended-SDRs) was from 7 to 128 amino acid sequence. Color variety in flowers and fruits is mainly the result of mutations in the genes involved in the anthocyanin biosynthesis pathway. Many genetic loci are well known for affecting color change or colorless traits. Furthermore, some of these have been revealed to be structural genes encoding enzymes in the biosynthesis pathway (Holton \& Cornish, 1995; Bharti \& Khurana, 2003), while others are regulatory genes controlling whole or subsets of structural genes (Yamazaki et al., 2003). Kim et al. (2004) reported that the lack of dihydroflavonol 4-reductase (DFR) transcription in yellow onions is responsible for the color difference between yellow and red onions. The mutant analyses demonstrated that in corresponding mutants of

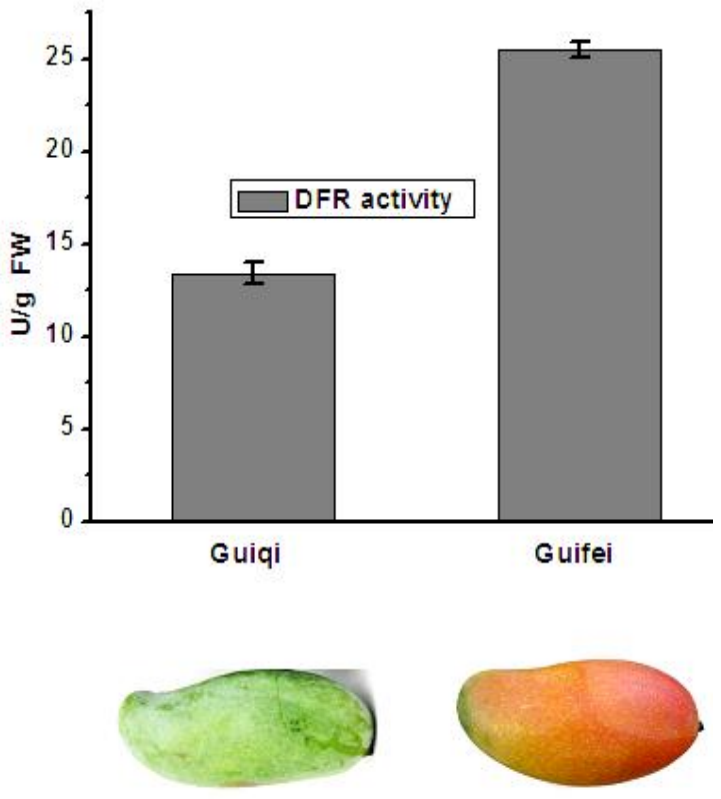

Figure 5 Assay of DFR activity in the green, and red mango peels throughout the growing season (The values are means $\pm S D ; n=3$ )

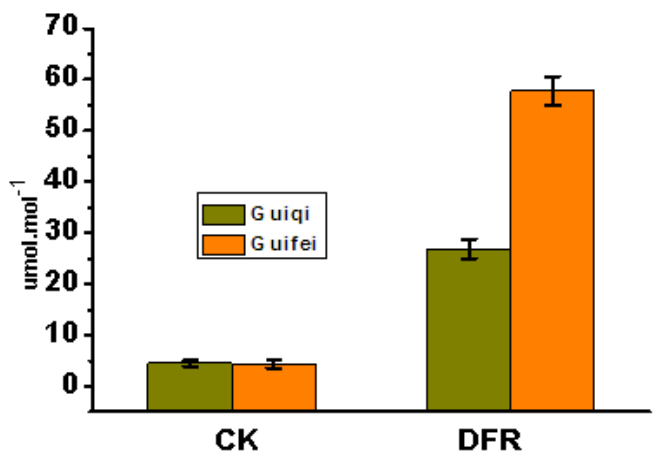

Figure 6 In vitro expression of DFR proteins from different color mango peels. (The values are means $\pm \mathrm{SD} ; \mathrm{n}=3$ ) 
the DFR genes a consistent fruit and flower color phenotype could be observed in plant. The generation of DFR mutants might be functionally redundant in fruits and flowers. In general, random generates mutations without losing gene function, such as inframe mutations (multiple of -3 ntdeletion) or silent mutations (without changes in the amino acid sequence). The deletion of amino acid might result in the failure of forming stacked saturated and aromatic rings, with lost enzyme activity. In present study, isolation of DFR cDNA genome from different color mango peel, and the successful invitro expression of $D F R$ have been reported. The mRNA of $D F R$ was measured in two different color mango peels, the levels consistence with the contents of anthocyanidin in two different colors. Over expression of $D F R$ was correlated with anthocyanin accumulations in the mango peel. These results indicate that DFR successfully interacted with anthocyanin biosynthetic pathway in the mango peel. Further molecular study is required to evaluate DFR activity and to identify other biosynthetic genes which are involved in the anthocyanidin synthase (ANS) and flavonoid synthesis pathway of mango. Expression analyses of these genes would reveal the possible reason of competition and/or blockage in the anthocyanin biosynthesis pathway within mango. These results imply that, although the boiosynthetic palthways share a majority, of common reactions in plant species, there are some important differences among the types of anthocyanin produced by each species.

\section{Acknowledgments}

This work was supported by "National Natural Science Foundation of China" (31471850), "National key research and development plan" (2018YFD1000500) ,"the Fundamental Scientific Research Funds for CATAS-TCGRI" (Project No. 1630032017004, 1630032017005). The anthour thank He junhu, Yang ziqin, and Li songgang in Tropical Crops Genetic Resources Institute, Chinese Academy of Tropical Agricultural Sciences.

\section{Conflict of Interest: All the authors have no conflict of interest}

\section{References}

Bharti A, Khurana J (2003) Molecular characterization of transparent testa (tt) mutants of Arabidopsis thaliana (ecotype Estland) impaired in flavonoid biosynthesis pathway. Plant Science 165:1321-1332.

Cheng H, Li L, Cheng S, Cao F, Xu F, Yuan H (2013) Molecular cloning and characterization of three genes encoding dihydroflavonol-4- reductase from Ginkgo biloba in anthocyanin biosynthetic pathway. PLoS ONE 8:e72017.

Cominelli E, Galbiati M, Vavasseur A, Conti L, Sala T, Vuylsteke M, Dellaporta SL, Tonelli C (2005) A guard-cell-specific MYB transcription factor regulates stomatal movements and plant drought tolerance. Current Biology 15:1196-1200.

Davies BH (1976) Carotenoid. In: Goodwin TW (ed) Chemical biochemistry plant pigments. Academic Press, New York.

Dixon RA, Piava NL (1995) Stress-induced phenylpropanoid metabolism. Plant Cell 7:1085-1097.

Fischer TC, Halbwirth H, Meisel B, Stich K, Forkmann G (2003) Molecular cloning, substrate specificity of the functionally expressed dihydroflavonol 4-reductases from Malus domesticaand Pyrus communis cultivars and the consequences for flavonoid metabolism. Archives Biochemistry Biophysics 412:223-230.

Forkmann G, Martens S (2001) Metabolic engineering and applications of flavonoids. Current Opinion in Biotechnology 12:155-160.

Harborne JB, Williams CA (2000) Advances in flavonoid research since 1992. Phytochemistry 55:481-504.

Heller W, Forknlan G, Britsch L, Grisebach H (1985) Enzymatic reduction of (+)-dihydroflavonols to flavan-3,4-cis-diols with flower extracts from Matthiola incana and its role in anthocyanin biosynthesis. Planta 165: 284-287.

Himi E, Noda K (2004) Isolation and location of three homologous clihyclroflavonol-4-recluctase (DFR) genes of wheat and their tissue-dependent expression. Journal of Experimental Botany 55:365-375.

Holton TA, Cornish EC (1995) Genetics and biochemistry of anthocyanin biosynthesis. Plant Cell 7:1070-1083.

Huang Y, Gou J, Jia Z, Yang L, Sun Y, Xiao X (2012) Molecular cloning and characterization of two genes encoding dihydroflavonol-4-reductase from Populus trichocarpa. PLoS ONE 7:e30364.

Inagaki Y, Johzuka-Hisatomi Y, Mori T, Takahastli S, Hayakawa Y, Peyachoknagul S, Ozeki Y, lida S (1999) Genomic organization of the genes encoding dihydroflavonol 4-reductase for flower pigmentation in the Japanese and common morning glories. Gene 226:181-188.

Kim S, Binzel M, Yoo K, Park S, Pike L (2004) Inactivation of DFR (dihydroflavonol 4-reductase) gene transcription results in blockage of anthocyanin production in yellow onions (Allium cepa). Molecular Breeding 14:253-263.

Kristiansen KN, Rohde W (1991) Structure of the Hordeum vulgare gene encoding dihydroflavonol-4-reductase and molecular analysis of ant18 mutants blocked in flavonoid synthesis. Molecular Genetics and Genomics 230:49-59.

Lee J, Durst RW, Wrosltad RE (2005) Determination of total monomeric anthocyanin pigment content of fruit juices, beverages, 
matural colorants, and wines by the $\mathrm{pH}$ differential method: collaborative study. Journal of AOAC International 88: 1269-1278.

Li Y, Shan X, Gao R, Yang S, Wang S, Gao X (2016) Two IIIf cladebHLHs from Freesia hybrida play divergent roles in flavonoid biosynthesis and trichome formation when ectopically expressed in Arabidopsis. Scientific Reports 6:30514.

Martens S, Teeri T, Forkmann G (2002) Heterologous expression of dihydroflavonol 4-reductases from various plants. FEBS Letters 531:453-458.

Miller R., Owens SJ, Rørslett B (2011) Plants and color: flowers and pollination. Optics \&. Laser Technology 43: 282-294.

Moyano E, Martinez-Garcia JF, Martin C (1996) Apparent redundancy in myb gene function provides gearing for the control of flavonoid biosynthesis in Antirrhinum flowers. Plant Cell 8:1519-1532.

Park JS, Kim JB, Hahn BS, Kim KH, Ha SH, Kim JB, Kim YH (2004) EST analysis of genes involved in secondary metabolism in Camellia sinensis (tea), using suppression subtractive hybridization. Plant Science166:953-961.

Piero AR.L, Puglisi I, Petrone G. (2006) Gene characterization, analysis of expression and in vitro synthesis of dihydroflavonol 4reductase from [Citrus sinensis (L.) Osbeck]. Phytochemistry 67:684-695

Rosati C, Cadic A, Duron M, Renou JP, Simoneau P (1997) Molecular cloning and expression analysis of dihydroflavonol 4reductase gene in flower organs of Forsythia 3 intermedia. Plant Molecular Biology 35:303-311.

Shih CH, Chu IK, Yip WK, Lo C (2006) Differential expression of two flavonoid 3-o-hydroxylase cDNAs involved in biosynthesis of anthocyanin pigments and 3-deoxyanthocyanidin phytoalexins in sorghum. Plant and Cell Physiology 47:1412-1419.

Shimada N, Sasaki R, Sato S, Kaneko T, Tabata S, Aoki T (2005) A comprehensive analysis of six dihydroflavonol 4-reductases encoded by a gene cluster of the Lotus japonicus genome. Journal of Experimental Botany 56:2573-2585.

Shirley BW, Kubasek WL, Storz G, Bruggemann E, Koornneef M, Ausubel FM, Goodman HM (1995) Analysis of Arabidopsis mutants deficient in flavonoid biosynthesis. The Plant Journal 8:659-671.

Singh K, Kumar S, Yadav SK, Ahuja PS (2009) Characterization of dihydroflavonol 4-reductase cDNA in tea [Camellia sinensis (L.) O. Kuntze]. Plant Biotechnology Reports 3: 95-101.

Staford HA, Lester HH (1982) Enzymic and nonenzymic reduction of(+) dihydroquercetin to its 3,4-diol. Plant Physiology 70 : 695-698.

Staford HA, Lester HH (1984) Flavan-3-ol biosynthesis the conversion of $(+)$ dihydroquercetin and flavan-3, 4-cis-diol (1euocyanidin)to(+) catechin by reductases extracted from cell suspension cultures of Douglas fir. Plant Physiology 76 : 184-186.

Stewart CN, Via LE (1993) A rapid CTAB DNA isolation technique useful for RAPD fingerprinting and other PCR applications. Biotechniques 5: 748-750.

Sui X, Gao X, Ao M, Wang Q, Yang, D, Wang M (2011) cDNA cloning and characterization of UDP-glucose: anthocyanidin 3-Oglucosyltransferase in Freesia hybrida. Plant Cell Reports 30:1209-1218.

Sun W, Liang L, Meng X, Li Y, Gao F, Liu X (2016) Biochemical and molecular characterization of a flavonoid 3-Oglycosyltransferase responsible for anthocyanins and flavonols biosynthesis in Freesia hybrida. Frontiers in Plant Science 7:410.

Sun W, Meng X, Liang L, Jiang W, Huang YHJ (2015) Molecular and biochemical analysis of chalcone synthase from Freesia hybrid in flavonoid biosynthetic pathway. PLoS ONE 10:e0119054.

Tanaka Y, Fukui Y, Fukuchi MM, Holton TA, Higgins E, Kusumi $\mathrm{T}$ (1995) Molecular cloning and characterization of Rosa hybrida dihydroflavonol 4-recluctase gene. Plant and Cell Physiology 36:1023-1031.

Wan C, Wilkins TA (1994) A modified hot borate method significantly enhances the yield of high-quality RNA from cotton (Gossypium hirsutum L.). Analytical Biochemistry 223:7-12.

Wang H, Fan W, Li H, Yang J, Huang J, Zhang P (2013) Functional characterization of Dihydroflavonol-4-reductase in anthocyanin biosynthesis of purple sweet potato underlies the direct evidence of anthocyanins function against abiotic stresses. PLoS ONE 8:e78484.

Weisshaar B, Jenkins GI (1998) Phenylpropanoid biosynthesis and its regulation. Current Opinion Plant Biology 1:251-257.

Winkel-Shirley B (2001) Flavonoid biosynthesis: a colorful model for genetics, biochemistry, cell biology, and biotechnology. Plant physiology 126:485-493.

Xie DY, Jackson LA, Cooper JD, Ferreira D, Paiva NL (2004) Molecular and biochemical analysis of two cDNA clones encoding dihydroflavonol-4-reductase from Medicago truncatula. Plant Physiology 134:979-994.

Yamazaki M, Makita Y, Springob K, Saito K (2003) Regulatory mechanisms for anthocyanin biosynthesis in chemotypes of Perilla frutescens var. crispa. Biochemical Engineering Journal 14:191-197.

Yang ZD, Zhai WW (2010) Optimization of microwave-assisted extraction of anthocyanins from purple corn (Zea mays L.) cob and identification with HPLC-MS. Innovative Food Science and Emerging Technologies 11: 470-476. 